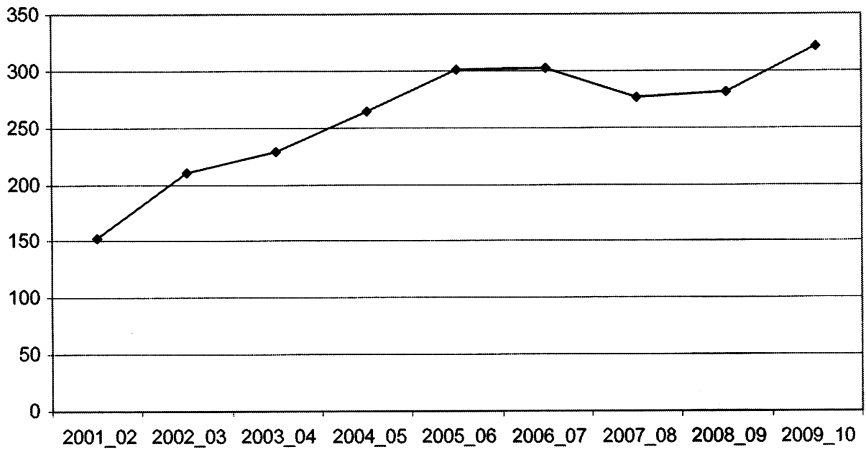

Abstract S7 Figure 1 Number of adult asthma admissions at Whipps Cross Hospital.

attendances were stable for children ranging from 442 in 2003/4 to 455 in 2008/9, but rose sharply to 652 in 2009/10. Adult emergency attendances decreased from 666 in 2003/4 to 512 in 2008/9, but also rose sharply in $2009 / 10$ to 790 . Emergency adult reattendances for 0-28 days, 0-90 days and 0-365 days fell from 85, 128 and 227, respectively in 2003/4 to 38,64 and 142 in 2008/9. From 2001/2 to 2009/10, there were 3707(2341 adult, 1366 children) hospital asthma admissions. Out of 1599 adult patients over this period, 1225 had just one admission. Admissions rose from 98 to 191 for children and 153 to 322 for adults from 2001/2 to 2009/10. Hospital adult readmissions have varied, ranging from 5(2001/2) to 16(2008/9) for $0-28$ days, $14(2003 / 4)$ to $35(2005 / 6)$ for $0-90$ days and 35 $(2002 / 3)$ to $68(2005 / 6)$ for $0-365$ days. Mean length of stay fell from 5.80 days in 2001/2 to 3.88 days in 2009/10.

Conclusions Large numbers of patients attend our emergency department for acute asthma. Admissions for acute asthma have risen markedly, more than doubling over 9 years. Numbers of readmissions within 28 days are relatively small, but the readmission rate within one year is relatively high at $22.70 \%(2008 / 9)$. These figures have important implications for resource allocation and training across the primary/secondary care divide.

\section{S8 THE NATIONAL COPD RESOURCES AND OUTCOMES PROJECT (NCROP): ACTION PLAN ACHIEVEMENT SINCE 2007}

doi:10.1136/thx.2010.150912.8

${ }^{1} \mathrm{~J} F$ O'Reilly, ${ }^{2} \mathrm{~N}$ A Pursey, ${ }^{2,3} \mathrm{C} \mathrm{M}$ Roberts, ${ }^{2,4} \mathrm{R}$ A Stone. ${ }^{1}$ Aintree University Hospital, Liverpool, UK; ${ }^{2}$ Clinical Standards Department, Royal College of Physicians, London, UK; ${ }^{3}$ Barts and the London School of Medicine and Dentistry, Queen Mary University of London, London, UK; ${ }^{4}$ Taunton and Somerset NHS Foundation Trust, Taunton, UK

Introduction and Objectives In 2007, 100 acute respiratory units participated in the NCROP, a randomised controlled study to assess whether reciprocal peer review could facilitate service improvement. We identified themes in desired improvements and evaluated success in meeting action plan aims.

Methods Units were paired and randomised into intervention or control arms (54:46). Intervention teams undertook reciprocal peer review in 2007 and documented action plans for service improvement. In 2010, intervention units self-assessed their progress in achieving action plans. Qualitative responses were analysed using a grouped themes approach to derive action plan themes.

Results Data were received from 41 of 54 intervention units (76\%). The Abstract S8 Table 1 shows the distribution of themes and action plan outcomes.
Abstract S8 Table 1

\begin{tabular}{|c|c|c|c|c|c|}
\hline Action Plan theme & $\begin{array}{l}\text { Number } \\
n\end{array}$ & $\begin{array}{l}\text { Met in full } \\
n(\%)\end{array}$ & $\begin{array}{l}\text { Partially met } \\
\text { n }(\%)\end{array}$ & $\begin{array}{l}\text { Not met } \\
n(\%)\end{array}$ & $\begin{array}{l}\text { Not recorded } \\
\text { n }(\%)\end{array}$ \\
\hline $\begin{array}{l}\text { Multi-disciplinary team } \\
\text { development }\end{array}$ & 41 & $13(32)$ & $21(51)$ & \begin{tabular}{|ll}
6 & $(15)$
\end{tabular} & $1 \quad(2)$ \\
\hline Non Invasive Ventilation & 32 & $11 \quad(34)$ & $13(41)$ & $7(22)$ & (3) \\
\hline Pulmonary Rehabilitation & 26 & $10 \quad(38)$ & $10 \quad(38)$ & $5(19)$ & (4) \\
\hline Domiciliary oxygen & 24 & $12(50)$ & $7(29)$ & $4(17)$ & 1 (4) \\
\hline Early Discharge & 21 & $7 \quad(33.3)$ & $9(43)$ & $4(19)$ & $\begin{array}{ll}1 & (5) \\
\end{array}$ \\
\hline Palliative care & 12 & $2(17)$ & $8(66.6)$ & $1(8)$ & $1 \quad(8)$ \\
\hline Clinical Audit & 7 & $1 \quad(14)$ & $3(43)$ & 1 (14) & $2(29)$ \\
\hline Respiratory Ward & 4 & $2 \quad(50)$ & 0 & $2(50)$ & 0 \\
\hline Guideline implementation & 3 & $1 \quad(33.3)$ & $1(33.3)$ & 0 & $1(33.3)$ \\
\hline IT database & 2 & 0 & $1(50)$ & $1(50)$ & 0 \\
\hline Patient Education & 1 & 0 & 0 & $1(100)$ & 0 \\
\hline
\end{tabular}

Conclusions Action plan themes related predominantly to development of multi-disciplinary teams across primary and secondary care and to specialist service provision. Most aims were fully achieved in a third of units and partially achieved in a similar number. Palliative care plans were less prevalent although at least partially successful in two thirds. Overall change was greater than in the 1 year assessment of the NCROP audit $2008 .^{1}$

\section{REFERENCE}

1. Roberts CM, Stone RA, Buckingham RJ, et al. A randomised trial of peer review: the UK National Chronic Obstructive Pulmonary Disease Resources and Outcomes Project. Clinical Medicine 2010;10:223-7.

\section{S9 FEASIBILITY OF ESTABLISHING A REGIONAL WEANING UNIT IN SCOTLAND: MODELLING RESOURCE IMPLICATIONS AND COSTS}

doi:10.1136/thx.2010.150912.9

${ }^{1} \mathrm{~N}$ I Lone, ${ }^{2} \mathrm{D}$ Sorensen, ${ }^{1} \mathrm{~T}$ S Walsh. ${ }^{1}$ University of Edinburgh, Edinburgh, UK; ${ }^{2} \mathrm{NHS}$ Lothian, Edinburgh, UK

Introduction Intensive care (ICU) admission is usually mandatory for patients requiring mechanical ventilation (MV). A proportion of patients require prolonged $\mathrm{MV}(\mathrm{PMV})$. In other countries, specialised weaning units allow stable PMV patients to be discharged from the ICU. These units offer cost savings because of lower staff-to-patient ratios. A recent report of UK ICU services recommended that hospitals review the need for specialised weaning centres locally

Aims To assess the feasibility of establishing a weaning unit in a Scottish health board region and to model the potential impact on ICU services.

Methods All admissions to the three adult ICUs in our health board requiring PMV ( $\geq 21$ days MV) during a 2-year period (2005-2006) were extracted from the Scottish Intensive Care Audit Group database. Four hypothetical weaning units were modelled using different admission criteria, ranging from Unit-A, which required a prolonged period of stability prior to transfer from ICU to the weaning unit (7 days free of both cardiovascular support (CVS) and renal replacement therapy), to Unit-D (2 days free of CVS only). The date of eligibility for each PMV patient for each unit was determined. We used remaining length of stay (LOS) in ICU after eligibility to calculate occupancy rate, refusal rate and net cost saving, varying unit capacity from 1 to 8 beds

Results During 2005-2006, 126 patients required PMV. Of these, the number eligible for transfer to a weaning unit varied from 101 (Unit-A) to 117 (Unit-D). Mean ICU LOS after reaching eligibility varied from 14.9 to 15.3 days. Occupancy rates for Unit-A ranged from $90.8 \%$ to $25.5 \%$ (1-bed to 8-bed unit) and for Unit-D from $93.3 \%$ to $30.5 \%$. Refusal rates for Unit-A ranged from $88.1 \%$ to $0 \%$, and for Unit-D $92.3 \%$ to $0 \%$. The greatest cost saving was for Unit$\mathrm{D}$ with 3 beds ( $\$ 344025)$ (Abstract S9 Figure 1). 


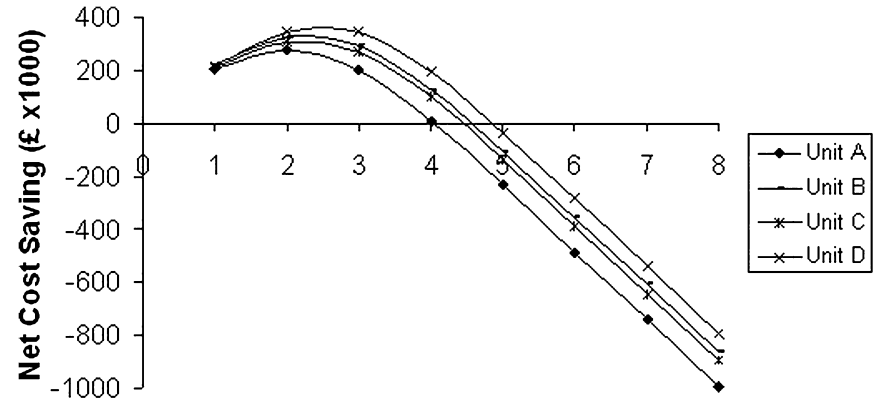

Number of Beds in Weaning Unit

Abstract S9 Figure 1 Modelling net cost saving of establishing a weaning unit by varying capacity from 1 to 8 beds.

Conclusion PMV patients use $25 \%$ of ICU bed-days in our region. Establishing a 3-bed weaning unit could lead to a reduction of 800 ICU bed-days, a net annual cost saving of $£ 340000$, and acceptable occupancy $(70 \%)$ and refusal $(30 \%)$ rates. Establishing such a unit would be feasible in our health board region.

\section{S10 IS IT COST-EFFECTIVE TO REPLACE NURSES WITH LAY ASTHMA EDUCATORS IN PRIMARY CARE?}

doi:10.1136/thx.2010.150912.10

${ }^{1} \mathrm{~N} J$ Roberts, ${ }^{1} \mathrm{~K}$ Boyd, ${ }^{1} \mathrm{~A}$ Briggs, ${ }^{2} \mathrm{~A} \mathrm{~L}$ Caress, ${ }^{3} \mathrm{M} \mathrm{R}$ Partridge. ${ }^{1}$ Health Economics Appraisal Team, Public Health and Health Policy, University of Glasgow, Glasgow, UK; ${ }^{2}$ Nursing, Midwifery and Social Work, University of Manchester, Manchester, UK; ${ }^{3} \mathrm{NHLI}$ Division at Charing Cross, Imperial College London, London, UK

Introduction Regular review of those with asthma and support for self-management is promoted in guidelines and encouraged by the Quality Outcomes Framework. Reasons for non-implementation include lack of time and training. A large randomised controlled trial in primary care suggested that need for unscheduled health care was similar if patients were reviewed and offered self management support by a trained lay educator compared to practice nurses. ${ }^{1}$

Methods A cost-effectiveness analysis was undertaken using the trial data. The cost of delivery for the intervention incorporated training and consultations. The measure of effectiveness was frequency of unscheduled healthcare which has also been costed.

Results One year intention to treat data $(n=418)$ showed that $29 \%$ $(61 / 205)$ of patients in the nurse group required unscheduled healthcare (177 events) compared with $30.5 \%(65 / 213)$ in the lay group (178 events), that is, there was no statistical difference in effect between the groups. Assigning a cost to this measure of effectiveness (unscheduled healthcare) provides $£ 161$ for nurses and $£ 135$ for lay trainers, that is, no significant difference (mean $£ 26$, (95\% CI $-95.61,146.69, \mathrm{p}=0.679)$ ). With regards to the costs of delivery, there was no significant difference between the two arms (mean difference $£-1.61(95 \% \mathrm{CI}-6.01,2.77, \mathrm{p}=0.4704)$ ). While the training costs for the lay trainers were greater than nurses ( $£ 35 \mathrm{vs}$ $£ 18$, respectively, per patient, $\mathrm{p}<0.001$ ), the consultation costs for lay trainers were lower than for nurses ( $£ 8$ per patient vs $£ 24$, $\mathrm{p}<0.001)$. The total costs, consisting of delivery and the measured outcome (unscheduled healthcare), were $£ 203$ per patient for the nurse arm vs $£ 179$ for lay trainers (mean difference $£ 24$, (95\% CI -97.15, 144.99, $\mathrm{p}=0.698)$ ).

Conclusion There was no significant difference in cost of delivery or in the effectiveness of the intervention between the two arms in this trial. It may be inappropriate to conclude that the intervention is not worthwhile as contracting lay trainers full-time rather than part-time would have made full use of the cost of their training, reducing the cost per patient and improving efficiency.
Funding Supported by the BUPA Foundation.

\section{REFERENCES}

1. Partridge MR, Caress AL, Brown C, et al. Can lay people deliver asthma selfmanagement education as effectively as primary care based practice nurses? Thorax 2008;63:778-83.

\section{S11 THE SOUTH EAST ESSEX (SEE) MODEL OF INTEGRATED COPD CARE AND OUIP (OUALITY INNOVATION AND PRODUCTIVITY) IMPROVEMENTS}

doi:10.1136/thx.2010.150912.11

${ }^{1} \mathrm{~A}$ G Davison, ${ }^{2} \mathrm{E}$ Paddison, ${ }^{2} \mathrm{C}$ Hanna, ${ }^{3} \mathrm{~S}$ Taylor. ${ }^{1}$ Southend University Hospital, Southend on Sea, UK; ${ }^{2}$ South East Essex PCT, Southend on Sea, UK; ${ }^{3}$ Southend PBC Group, Southend on Sea, UK

The coalition Government has announced there should be $£ 20$ billion saving over the next financial cycle in the health budget, and the QUIP (Quality, Innovation and Productivity) agenda is at the heart of this. The SEE model is an ongoing project of integrating COPD care across primary and secondary providers. A robust local network is at the centre of the project which includes increased Consultant community care (real and virtual), education of staff at the University of Essex, Hospital at Home, improved communication, increased community rehabilitation, community spirometry, improved pathways, self-management plans, oxygen alert cards, dedicated oxygen service and involvement of Breathe Easy. We have reviewed our data to see if productivity has improved in line with the QUIP agenda.

Results (See Abstract S11 Table 1) Oxygen provision has been reviewed in a three-step process starting with the highest tariffs and extending to all patients on oxygen resulting in $£ 250000$ saving per year.

\section{Abstract S11 Table 1}

\begin{tabular}{|c|c|c|c|}
\hline \multicolumn{4}{|c|}{ Summary of reduction in emergency COPD admissions, bed days and cost } \\
\hline Financial year & $07 / 08$ & $08 / 09$ & $09 / 10$ \\
\hline Number COPD admissions & 909 & 841 & 740 \\
\hline Number COPD bed days & 6969 & 5925 & 5327 \\
\hline Cost as per $2009 / 10 \mathrm{PbR}$ & $£ 2141259$ & $£ 2067171$ & $£ 1781052$ \\
\hline \multicolumn{4}{|c|}{$\begin{array}{l}\text { Reduced new (NP) to follow-up (FU) rations in respiratory outpatients. Indicates high } \\
\text { proportion of follow-up occurring in the community. }\end{array}$} \\
\hline Financial year & $07 / 08$ & $08 / 09$ & $09 / 10$ \\
\hline $\mathrm{NP} / \mathrm{FU}$ ratio & 2.95 & 2.9 & 2.7 \\
\hline
\end{tabular}

Conclusion Integrated services for COPD can bring care closer to home produce reduced admissions, reduced NP/FU ratios and saving on oxygen. Integrated services have achieved savings of at least $£ 650000$ per annum and this is line with the QUIP agenda.

\section{S12 PRE-CLINIC TELEPHONE CONSULTATIONS: A COSTING STUDY}

doi:10.1136/thx.2010.150912.12

${ }^{1} \mathrm{~L}$ O'Byrne, ${ }^{2} \mathrm{~N}$ J Roberts, ${ }^{2} \mathrm{~K}$ Boyd, ${ }^{2} \mathrm{~A}$ Briggs, ${ }^{1} \mathrm{M}$ R Partridge. ${ }^{1} \mathrm{NHLI}$ Division at Charing Cross Hospital, Imperial College London, London, UK; ${ }^{2}$ Health Economics Appraisal Team, Public Health and Health Policy, University of Glasgow, Glasgow, UK

Study of the taking of a patients' history by telephone prior to clinic attendance and co-ordinating investigations for new respiratory patients showed a reduction in hospital attendances with no 